\title{
Effect of ligand sensing on flagellar bundle formation in bacteria
}

\author{
Megha Agrawal ${ }^{1}$, Soumyadeep Chakraborty ${ }^{1}$, Mahesh S. Tirumkudulu ${ }^{1,2}$, and K.V \\ Venkatesh $^{1,2}$ \\ ${ }^{1}$ Department of Chemical Engineering, Indian Institute of Technology Bombay, Mumbai \\ 400076, India \\ ${ }^{2}$ Corresponding authors: mahesh@che.iitb.ac.in; venks@iitb.ac.in
}

June 11, 2021

\begin{abstract}
E. coli swims in liquid media by rotating long appendages called flagella. The direction of rotation of each flagellum is governed by a transmembrane rotary nanomotor, which receives signals from ligandspecific receptors. Attractants bias the motor to rotate in CCW direction causing flagella to bundle and provide thrust for locomotion. Recent studies have shown that sensing not only leads to increase in $\mathrm{CCW}$ bias but also increases the motor rotation speed due to the recruitment of additional stator units bound to the rotor. Despite the detailed studies on bacterial motility, the effect of ligand sensing on the synchronization of flagellar filaments leading to bundle formation and changes in bundle geometry are not clear. In this work, we performed real-time imaging of the flagellar bundle of swimming cells in metabolising (glucose) and non-metabolisable (2-Deoxy-d-glucose) attractants. We characterized bundles during swimming by measuring visible distal length and the spread of filaments at poles. We show that sensing of attractant by receptor leads to the formation of tight bundles when compared to control buffer. Contrary to previous studies, the swimming speeds were proportional to the bundle tightness with the latter dependent not only on the bias but also on the torque exerted by the motor. We further show that the observed wiggles in the swimming trajectory of cells is directly proportional to the spread angles of bundle and is effected by both motor CCW bias and torque. Mutant cells, which were rendered non-motile due to the absence of the PTS (phosphotransferase system) sugar uptake mechanism, exhibited motility when exposed to the non-metabolisable attractant confirming that mere sensing can induce torque in flagellar motor. These results clarify the role of sensing and metabolism on bundle formation and its impact on the motility of cells.
\end{abstract}

\section{Keywords}

Flagellar bundling, Sensing, Metabolism, Swimming speed, Torque

\section{Statement of significance}

Peritrichously flagellated E. coli swims away or towards ligands by biasing the direction of rotation of its flagellar motor. Recently, it has been shown that motor speed is also modulated on merely sensing a ligand. How does this impact flagellar bundle formation and swimming behavior? Using real-time imaging, we show that the bundle geometry changes in response to both metabolisable and non-metabolisable ligand. Mere sensing of a ligand temporarily increases the motor torque and CCW bias that causes tight flagellar bundles and leads to smooth swimming trajectories at high speeds. Our result provides strong evidence of a new signalling pathway that controls the flagellar motor speed to enable the bacteria to respond efficiently to changes in its environment. 


\section{Introduction}

Bacteria employ a sensory system to explore their environment to find the best-suited niche for their survival. E. coli is one of the most studied bacteria for its sensing mechanism. It is rod-shaped and propelled by several thin helical flagellar appendages (about 4-7) emerging from random locations on their cell body. Each flagellum has a basal body, a flexible hook and a extended flagellar filament $(\approx 5 \mu \mathrm{m})[1]$ driven by a membrane-embedded, torque generating motor $(\approx 50 \mathrm{~nm})$ which rotates in either clockwise $(\mathrm{CW})$ or counterclockwise $(\mathrm{CCW})$ direction [2]. When a cell swims in a medium, each flagellar filament's compliant hook enables them to self-organize into a coordinated bundle and push the cell in a forward direction. If one or more filaments change direction to CW, the flagellar filaments come apart from the bundle, causing a change in the swimming direction, termed as a tumble. Filaments are intrinsically left-handed helices but upon reversal to CW rotation, turn into right-handed (semi-coiled) with smaller diameter and pitch, that leads to dispersal of out-of-phase filament from the bundle [3]. Thus, tumbling occurs due to a combination of motor reversal and polymorphic changes in flagella and results in directional reorientation of the cell. When the cell swims, no external torque acts on the body and so the cell body rotates in a direction opposite to the rotating bundle so as to counter the torque exerted by the rotating bundle [4]. Three-dimensional tracking of $E$. coli reveals that the cell motion is akin to a random-walk motion constituting a sequence of runs (few seconds) and tumbles (fraction of a second) [5]. The directed motion towards attractants or away from repellents is thus achieved by a combination of run and tumble events. The swimming trajectory is not a straight line, but a helical curve of small radius [6], which is caused by the off-axis thrust exerted by sections of helical bundle. Large radius helical trajectories have also been observed in some bacteria due to either the off-axis position of the flagellar bundle relative to the cell body [7], or imbalance of mass distribution in the head [8].

In E. coli, a well-defined signaling pathway controls the direction of rotation of each flagellar motor. Five chemoreceptors specific for different ligands are clustered near the poles and they mediate signals via a cascade of proteins to the motor regulator protein, CheY $[9,10]$. In the phosphorylated state, CheY-P binds to FliM component of the motor switch complex and enables it to rotate in CW direction [11]. The presence of attractants reduces the level of CheY-P; thus, the motor rotates in CCW direction in the null state [9] (Figure 1). Recent evidence suggests that sensing not only modulates directional bias but also increased swimming speeds by as much as $28 \%(23.3 \mu \mathrm{m} / \mathrm{s}$ to $29.8 \mu \mathrm{m} / \mathrm{s}$ ) in E. coli in response to $\alpha$-methyl aspartate gradients [12]. Run speeds were higher in metabolisable ligands such as glucose compared to its non-metabolisable analogue 2-Deoxy-dglucose which are sensed by Trg receptor [13-15]. It was later shown that the increased swimming speeds correlates with the increased head rotation rates [14]. Further, the increased run speeds are accompanied with smoother swimming trajectories and reduced cell body wiggles $[5,13,16,17]$. Inside the cell, the structure of flagellar motor is dynamic as stator units assemble and disassemble in response to changes in load, proton motive force, thereby altering the motor speed [18-20]. More recently, the increased swimming speed has also been attributed to recruitment of stators upon sensing of an attractant, which is indicative of a new signalling pathway for motor control [21]. While the aforementioned studies have investigated the influence of ligands either on the signalling pathway, motor control or the final swimming motion, an important component responsible for bacteria's motion is also the bundle geometry and it's dynamics.

Much of the work on flagellar bundle has focused on the dynamics of bundle formation, via theory [22,23], experiments [16,24-26] and computer simulations [27-31]. In E. coli, the rotation of multiple flagella about their respective axis adds to the complexity in bacterial motion because rotational direction and speed are under the independent control of their motors. Interestingly, a cell with multiple flagella does not enable the cell to swim faster than a cell with a single flagellum since the thrust is a weak function of flagellar diameter [16]. Further, the tumbling probability is also independent of the number of flagella [32]. On the contrary, some marine bacteria with a single flagellum are able to choose a new swimming direction via buckling instability of the flagellum, also termed as a 'reverse and flick' mechanism [33] suggesting that 'run-and-turn' motion is possible even in the presence of a single flagellum. Soil bacteria such as Rhizobium meliloti are peritrichous like E. coli but their filaments undergo limited polymorphic transitions and are unidirectional as their 
bioRxiv preprint doi: https://doi.org/10.1101/2021.02.11.430483; this version posted June 11, 2021. The copyright holder for this preprint (which was not certified by peer review) is the author/funder. All rights reserved. No reuse allowed without permission.

motor can rotate only in CW direction [29]. Here, the bacteria change their swimming direction via rotational torque induced by applying different rotation speeds to individual flagellum. Thus it appears, that the role of multiple flagella in bacteria such as $E$. coli is to enable cells to choose a new direction after a tumble, more efficiently.

In the present study, we build on this understanding of bundle dynamics to investigate the influence of ligand sensing on the bundle geometry and the resulting swimming trajectory. Specifically, we determine how the sensing of metabolisable and non-metabolisable ligands influences the geometry of the flagellar bundle. The flagella geometry was visualized by tagging the flagellin proteins using aminospecific Alexa-fluor dyes, a technique pioneered by Berg and co-workers [34]. Since the compactness of the bundle is determined by both the motor bias and torque, we correlate the bundle geometry with motor performance via tethered cell assays. Cells were exposed to glucose, and its non-metabolisable analog 2-Deoxy-d-glucose (2Dg), which are sensed by the Trg receptor [10,35]. Glucose is also sensed and metabolised by the phosphotransferase system (PTS) pathway [36]. Experiments were conducted with wild-type E. coli RP437 (WT) and its $\operatorname{trg}$, cheY, ptsI gene deletion mutants. We show that both metabolism and sensing influence the bundle geometry via modulation of motor speed and bias, thereby effecting the motility of cell.

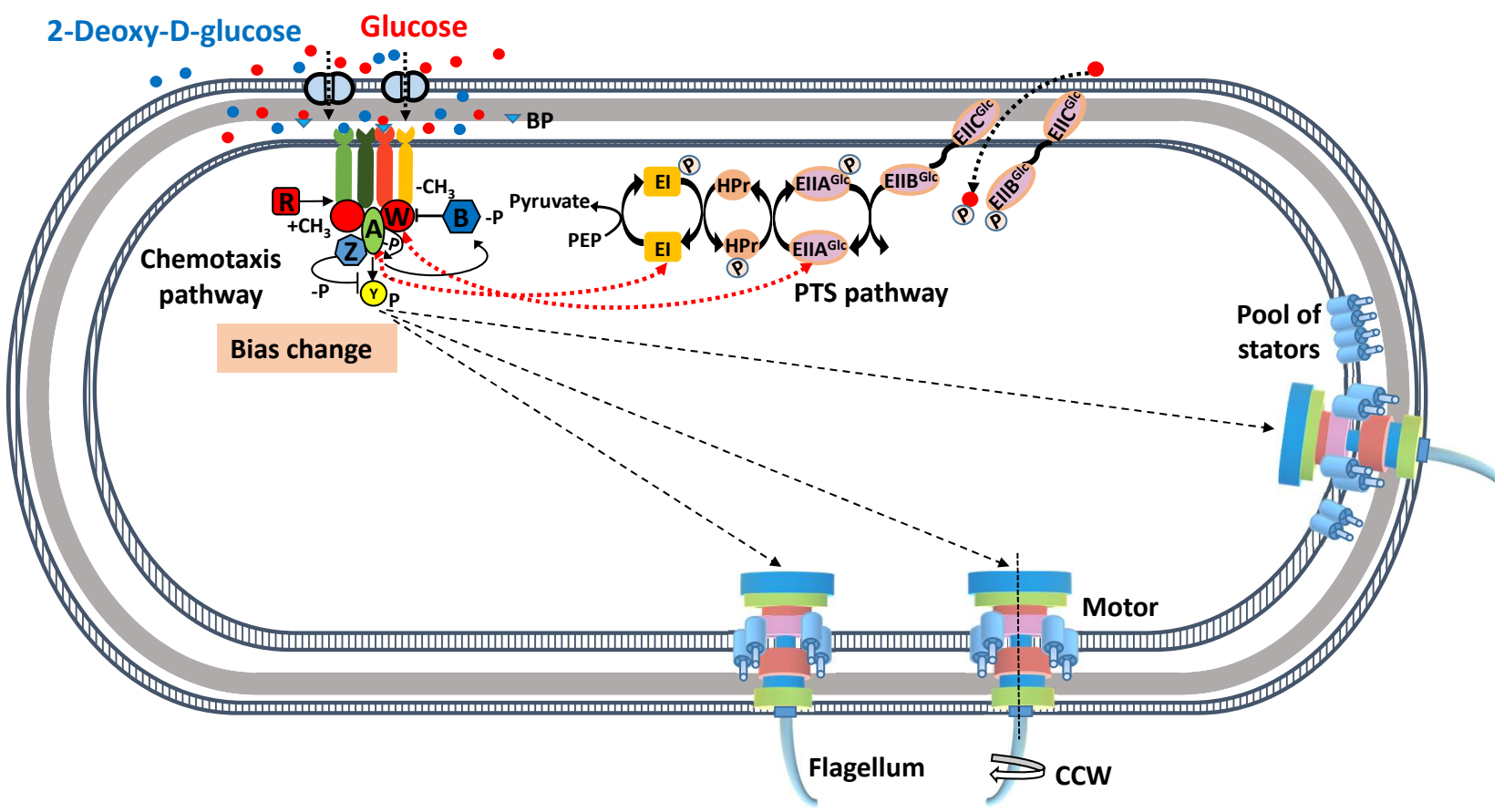

Figure 1: Transmembrane Trg receptor of the chemotaxis pathway signals the presence of attractants such as glucose and 2Dg to the flagellar motor via CheY protein. Phosphorylated state of CheY interacts with FliM of the rotor-switch complex of the motor, enabling them to rotate CW direction. Binding of an attractant activates CheA, which further activates the phosphatase activity of CheZ protein. CheZ dephosphorylates CheY and motor rotates uninterrupted in $\mathrm{CCW}$ direction. Additionally, glucose which is metabolisable ligand is also sensed by the PTS pathway whose signals integrate into the chemotaxis pathway. EI and EII both interact with CheA and CheW, and dictates the rotation via CheY $[36,37]$. Such varied signals dictate the direction of rotation of individual flagellum placed at different locations of the cell. Sensing might synchronize these individual flagella into stable bundle formation by decreasing the probability of $\mathrm{CW}$ reversals and thereby impacting the swimming speed of cells. The above figure is adapted from Naaz et.al [21]. 
bioRxiv preprint doi: https://doi.org/10.1101/2021.02.11.430483; this version posted June 11, 2021. The copyright holder for this preprint (which was not certified by peer review) is the author/funder. All rights reserved. No reuse allowed without permission.

\section{Results}

\section{Attractant sensing leads to smoother trajectories of $\boldsymbol{E}$. coli}

The wild-type E. coli cell population was exposed to a constant ligand concentration environment to measure the effect of sensing on the wiggling trajectories. The varying angular displacement about the mean swimming direction was quantified by measuring the apparent rotational diffusivity $\left(\mathrm{D}_{r}\right)$ (Figure 2A, see Materials and methods section) of at least 3000 cells for each case. An increase in $\mathrm{D}_{r}$ signifies an increase in wiggling while a reduction pertains to smoother runs. Figure 2B presents the rotational diffusivity measured as a function of time for cells after they were exposed to 1000 $\mu \mathrm{M} 2 \mathrm{Dg}$ and glucose along with the control (MB). Measurements were made at four different time points, namely, 1.5, 6.5, 11.5 and $16.5 \mathrm{~min}$, from the start of the experiment. Figure $2 \mathrm{~B}$ shows that the sensing of both attractants at two initial time points (1.5 and $6.5 \mathrm{~min}$ ) resulted in $34-38 \%$ lower values compared to respective MB data points. Glucose had a more pronounced effect than $2 \mathrm{Dg}$ as the $\mathrm{D}_{r}$ gradually reduced to $55 \%$ and $74 \%$ of $\mathrm{MB}$ at 11.5 and $16.5 \mathrm{~min}$, respectively. In the case of $2 \mathrm{Dg}$, $\mathrm{D}_{r}$ remained $48 \%$ lower than $\mathrm{MB}$ at $16.5 \mathrm{~min}$. All data points of glucose and 2Dg are significantly different from $\mathrm{MB}$ at $p<0.05$ as computed by paired student t-test (except for 2Dg at $11.5 \mathrm{~min}$ ). The trajectory of different cells in each buffer was also analyzed and the wiggling trajectories were approximated as helical paths in terms of pitch and radius (Figure 3B). In MB, the trajectory had a mean pitch of $1.50 \pm 0.32 \mu \mathrm{m}$ and a mean radius of $0.47 \pm 0.10 \mu \mathrm{m}$ (pitch/radius \pm standard deviation) averaged over 20 cells. In 2Dg, cells showed smoother trajectories with a pitch of $0.88 \pm$ $0.34 \mu \mathrm{m}$ and radius of $0.38 \pm 0.05 \mu \mathrm{m}$ averaged from 20 cells (Figure 3B). The trajectories in uniform glucose were smooth with no detectable wiggling. These results clearly demonstrate that the sensing of attractants reduces the wiggling in swimming trajectory and the reduction is more significant in metabolisable ligand compared to its non-metabolisable analogue. The results are in agreement with earlier reported study [13].

To further confirm that reduction in the $\mathrm{D}_{r}$ values is indeed an outcome of ligand sensing via the transmembrane receptor, experiments were repeated with $\mathrm{trg}$ gene mutant strain. Figure $2 \mathrm{C}$ shows that there was no significant difference in the values of $\mathrm{D}_{r}$ between $\mathrm{MB}$ and $2 \mathrm{Dg}$. The initial reduction in case of glucose was only $17 \%$ of $\mathrm{MB}(0 \mathrm{~min})$, whereas in WT, it was $38 \%$. However, glucose is also sensed by the phosphotransferase uptake pathway whose signal is integrated with the chemotaxis pathway [36]. Therefore, with time the $\mathrm{D}_{r}$ values gradually reduced to $78 \%$ of $\mathrm{MB}$ at $15 \mathrm{~min}$, similar to that achieved in WT.

\section{Swimming speed is inversely related to rotational diffusivity}

To find the relation between swimming speed and rotational diffusivity, both parameters were measured for WT and its mutants ( $\Delta \operatorname{trg}, \Delta c h e Y, \Delta p t s I$ RP437) in glucose and 2Dg at different times after ligand exposure. Figure 2D shows the consolidated graph where each data point is an average of at least 3000 cells. The speed of the cell population varies inversely with respective $\mathrm{D}_{r}$, as depicted by the fitted-solid curve.

\section{Glucose metabolism and sensing leads to tighter bundles}

To explore the reason for reduced angular displacements during sensing, flagellar proteins were stained to visualize the flagellar bundle of cells while swimming. The fluorescent-labeled WT cells were exposed to control buffer ( $\mathrm{MB}^{*}$, which has a different $\mathrm{pH}$ value as compared to $\mathrm{MB}$, see Materials and Methods section), and $1000 \mu \mathrm{M}$ of glucose and 2Dg. Figure 3A shows different configurations of flagellar bundles observed when a batch of WT cells was imaged in the uniform concentration of MB*. An average of 3-4 flagella were observed with curly configuration for a stationary cell (Figure 3A-1). Figure $3 \mathrm{~A}$ also shows bundles of swimming cells formed by WT in different ligands as compared to control buffer. Two bundles are seen in MB* (Figure 3A-2). The bundle in 2Dg shows a wider spread at the pole (Figure 3A-3) while glucose has a smaller spread angle (Figure 3A-4). The flagellar bundle in glucose appears as a long blurred tail which is in accordance to previous study [38]. However, neither 
bioRxiv preprint doi: https://doi.org/10.1101/2021.02.11.430483; this version posted June 11, 2021. The copyright holder for this preprint (which was not certified by peer review) is the author/funder. All rights reserved. No reuse allowed without permission.

A

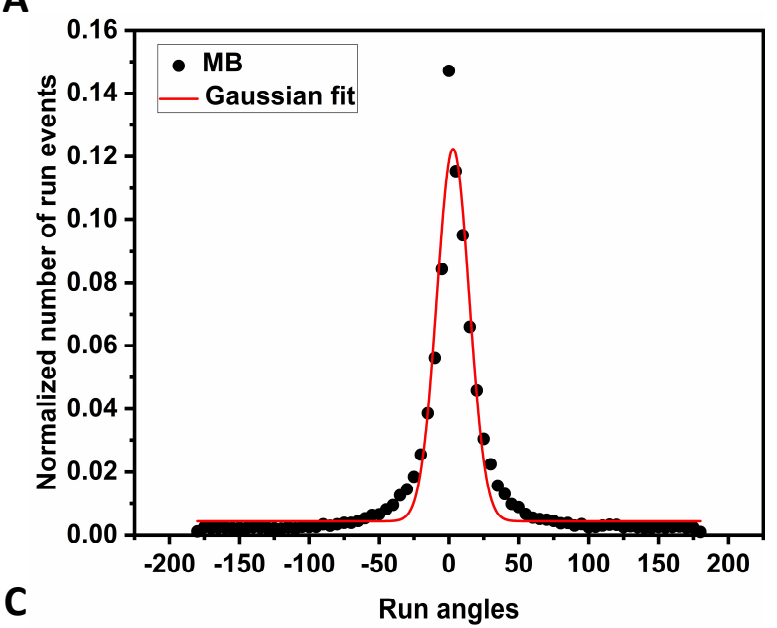

C

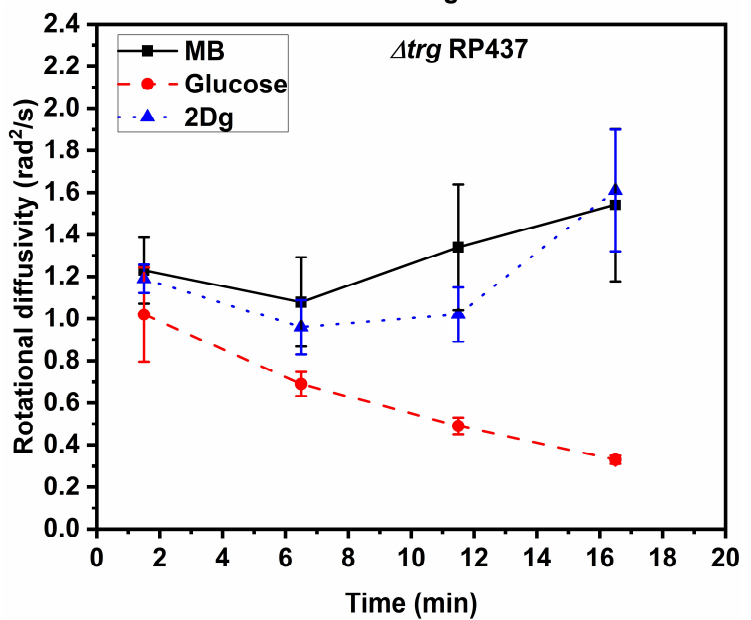

B
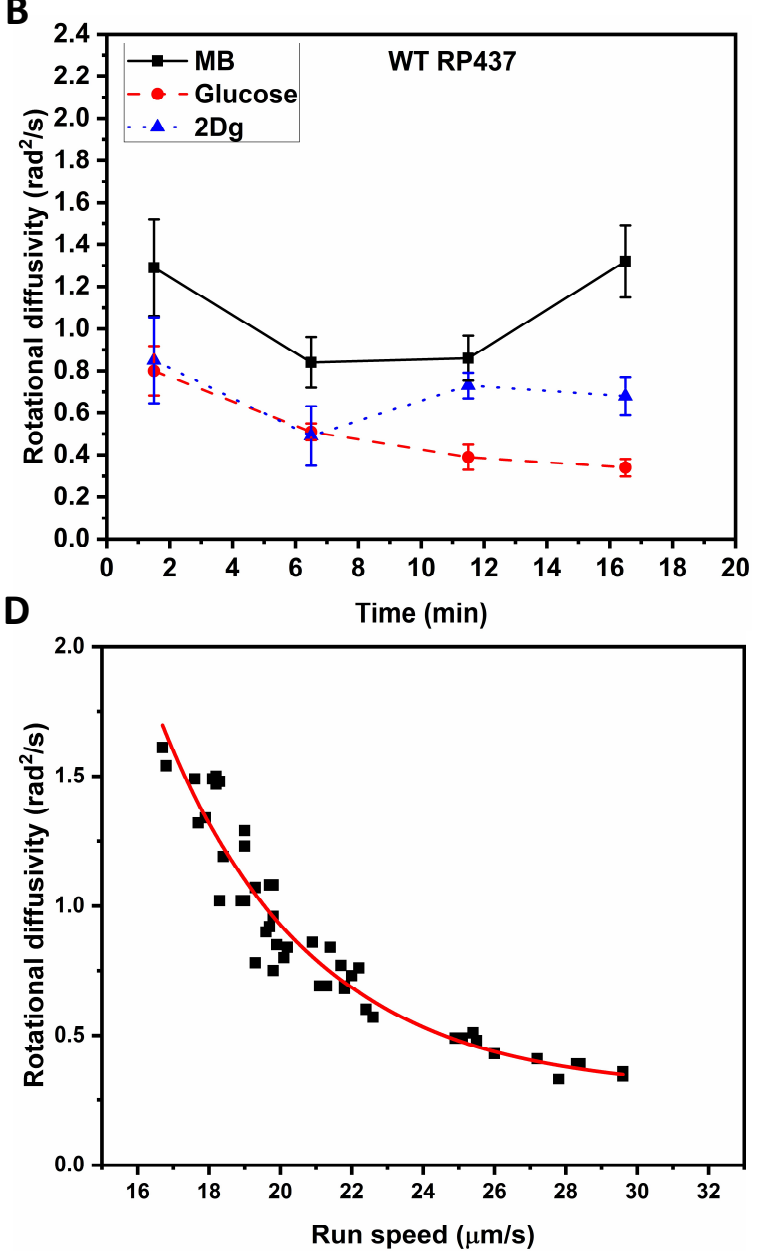

Figure 2: (A) The distribution of run angles for WT cell in MB (at 6.5 min) plotted against normalized number of run events for at least 3000 cells. The Gaussian curve is fit to obtain the standard deviation $\langle\theta\rangle^{2}$ so as to calculate the apparent rotational diffusivity, $\langle\theta\rangle^{2} / 2 t$ where $t=0.047 \mathrm{~s}$. Variation in rotational diffusivity with time in $1000 \mu \mathrm{M}$ glucose and $2 \mathrm{Dg}$ as compared with control buffer (MB) for (B) Wild type RP437. All data points of glucose and 2Dg are significantly different from MB at $p<0.05$ as computed by paired student t-test (except for $2 \mathrm{Dg}$ at $11.5 \mathrm{~min}$ ). (C) $\Delta \operatorname{trg} \mathrm{RP} 437$. All data points of glucose are significantly different from MB at $p<0.01$ as computed by paired student t-test. The difference in values of $\mathrm{MB}$ and $2 \mathrm{Dg}$ were insignificantly different from each other $(p>0.05$.) except at $11.5 \mathrm{~min}$. The time axis represents incubation period after ligand introduction. Error bars are standard errors from four independent experiments. (D) Rotational diffusivity is inversely proportional to the run speed of cells. Swimming speed and rotational diffusivity of each WT, $\Delta \operatorname{trg}$, $\Delta p t s I$, and $\Delta c h e Y$ RP437 strains were measured in MB, glucose, and 2Dg at four time points, 1.5, $6.5,11.5$, and $16.5 \mathrm{~min}$. Each data point is an average of at least 2500 cells from four independent experiments. The solid curve is an exponential fit for the data points. 
bioRxiv preprint doi: https://doi.org/10.1101/2021.02.11.430483; this version posted June 11, 2021. The copyright holder for this preprint (which was not certified by peer review) is the author/funder. All rights reserved. No reuse allowed without permission.

the helicity of individual flagellum nor the total number of flagella in an E. coli could not be detected due to the high rotation speed of the flagella.

For quantifying bundle geometry, its length and spread at the pole were measured as described in the supplementary information (see supplementary information, S1A). The spread angle quantifies the compactness of the bundle. The bundle length reported here is the measured projected length and may not be the true measure of flagella length since flagella length is highly dependent on culture condition, cell preparation methodology and imaging condition. The apparent bundle lengths across various mutants in different ligands were observed to be in the range of 1.5-6 $\mu \mathrm{m}$ which is in agreement with the values reported earlier in Alexa fluor 488 labelled E. coli AW405 (5.6 $\pm 2.9 \mu m)$ [24]. Also, the filaments lengths were shorter in Alexa fluor 488 as compared to other dyes due to its chemical effects that might render the filaments brittle [24]. Since the goal is to determine relative changes in bundle length and spread angle, the shortness of individual filaments is not expected to influence the final results. Images of about 25-40 individual cells, each of WT, $\Delta \operatorname{trg}$, and $\Delta p t s I$ RP437 strains, were analyzed to extract these two parameters, each in $\mathrm{MB}^{*}$, glucose, and 2Dg environment (Figure 3C-F). WT showed an average spread angle of $62^{\circ} \pm 12^{\circ}$ (angle \pm standard deviation) in $\mathrm{MB}^{*}$, an intermediate spread of $44^{\circ} \pm 10^{\circ}$ in $2 \mathrm{Dg}$ and the smallest spread angle of $24^{\circ} \pm 4^{\circ}$ in glucose (Figure $3 \mathrm{C}$ ). In MB*, cells exhibited either loose single bundles or multiple bundles. On the other hand cells exposed to 2Dg and glucose showed only a single bundle. Apparent bundle length varied inversely with spread angle with the longest bundles observed in glucose. Thus, the sensing of ligand appears to synchronize the movement of individual filaments so as to form long, single, tight bundles.

A similar experiment was also conducted with $\Delta \operatorname{trg}$ RP437. It showed an average flagellar spread angle of $48^{\circ} \pm 9.2^{\circ}$ in $\mathrm{MB}^{*}$ and $46^{\circ} \pm 9.4^{\circ}$ in $2 \mathrm{Dg}$, whereas in glucose it was around $26^{\circ} \pm 7.9^{\circ}$ (Figure $3 \mathrm{D}$ ). The absence of Trg receptor eliminates signal transduction due to sensing of $2 \mathrm{Dg}$ leading to spread angles similar to those observed in $\mathrm{MB}^{*}$. These results confirm the analogous trend observed for $\mathrm{D}_{r}$ (Figure 2C). The bundling parameters in glucose were unaffected by Trg receptor's absence and were similar to those observed for WT in glucose. It is evident from these experiments that sensing of glucose by Trg receptor and PTS uptake system both result in tighter flagellar bundles. This is not surprising given that the PTS uptake system reduces the phosphorylation of CheA, which in turn decreases the concentration of CheY-P, and therefore biases the motor towards CCW rotation.

Since glucose metabolism is controlled by the PTS pathway, $\Delta p t s I$ RP437 strain was used to investigate the role of sensing via PTS pathway on the compactness of bundles. $\Delta p t s I$ cells showed an increased spread angle of $36^{\circ} \pm 22^{\circ}$ in glucose, which is highest compared to WT and $\Delta \operatorname{trg}$ strains in the same media. The spread angle for $2 \mathrm{Dg}$ was $52^{\circ} \pm 38^{\circ}$ (Figure $3 \mathrm{E}$ ). We could not obtain sufficient data in $\mathrm{MB}^{*}$ since flagella were completely unbundled leading to negligible motility.

\section{Absence of CheY response regulator resulted in tight bundles}

The response regulator protein, CheY was deleted, and the flagellar bundle parameters were measured. The responses for $\mathrm{MB}^{*}$, glucose, and $2 \mathrm{Dg}$ were indistinguishable as all cells showed tight bundles (Figure $3 \mathrm{~F}$ ). The spread angle were in the range of $26-30^{\circ}\left( \pm 12^{\circ}\right)$. The values of the spread angle were similar to that of glucose as obtained for WT and $\Delta \operatorname{trg}$ cells. This suggests that when all the flagella rotate in the $\mathrm{CCW}$ direction, the bundle is compact leading to negligible wiggling.

\section{Swimming speed is inversely related to spread angle}

Since ligand sensing synchronizes the flagellar rotation to form tighter bundles in presence of ligands as compared to control buffer, we investigated whether this influences the run speed of cells. The run speed of WT cells in $\mathrm{MB}^{*}$, glucose, and 2Dg were plotted against their respective average spread angle. Figure $4 \mathrm{~A}$ shows that speed was inversely related to the spread angle as depicted by the exponential fit. Tight bundles with the highest speeds were obtained in glucose reaching $23 \mu \mathrm{m} / \mathrm{s}$. For $2 \mathrm{Dg}$, all data points lie in between those for glucose and MB*. The maximum speed was around $13 \mu \mathrm{m} / \mathrm{s}$ in 2Dg. In $\mathrm{MB}^{*}$, we obtained considerably lower speeds as compared to earlier reported speeds of $18.8 \pm$ $8.2 \mu \mathrm{m} / \mathrm{s}$ [39]. The reduced speed for the dyed cells can be attributed to not only shorter bundles but also to the effect of the laser beam. It is well known that light of wavelength $510 \mathrm{~nm}$ or lower reduce 
A
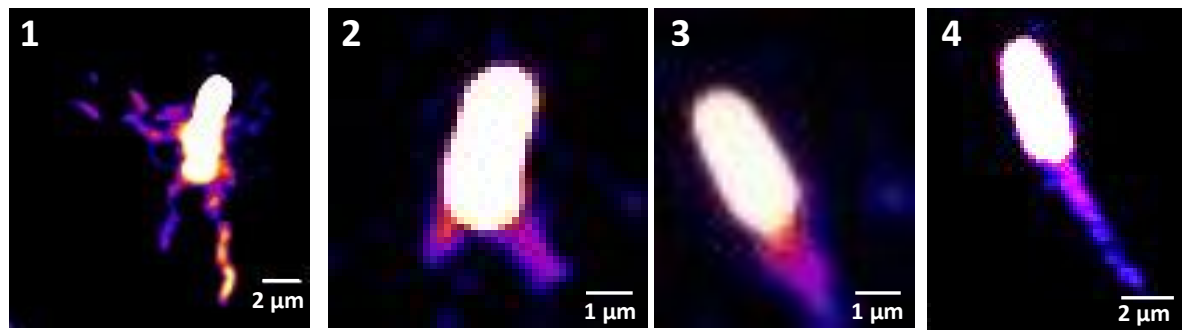

B

Trajectories of different WT cells
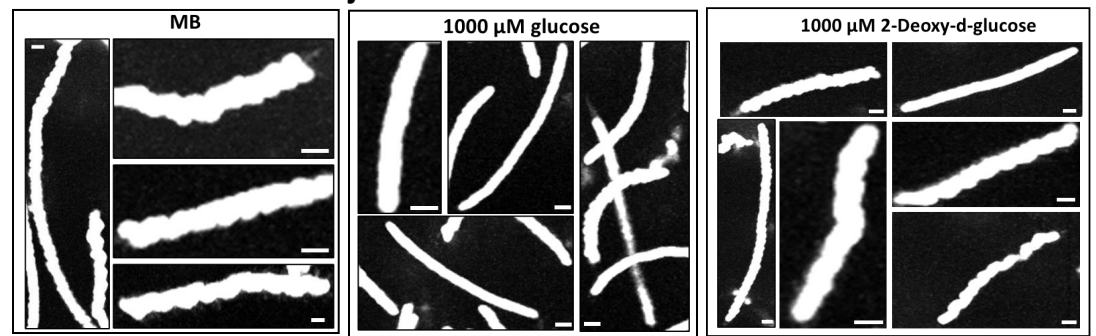

C
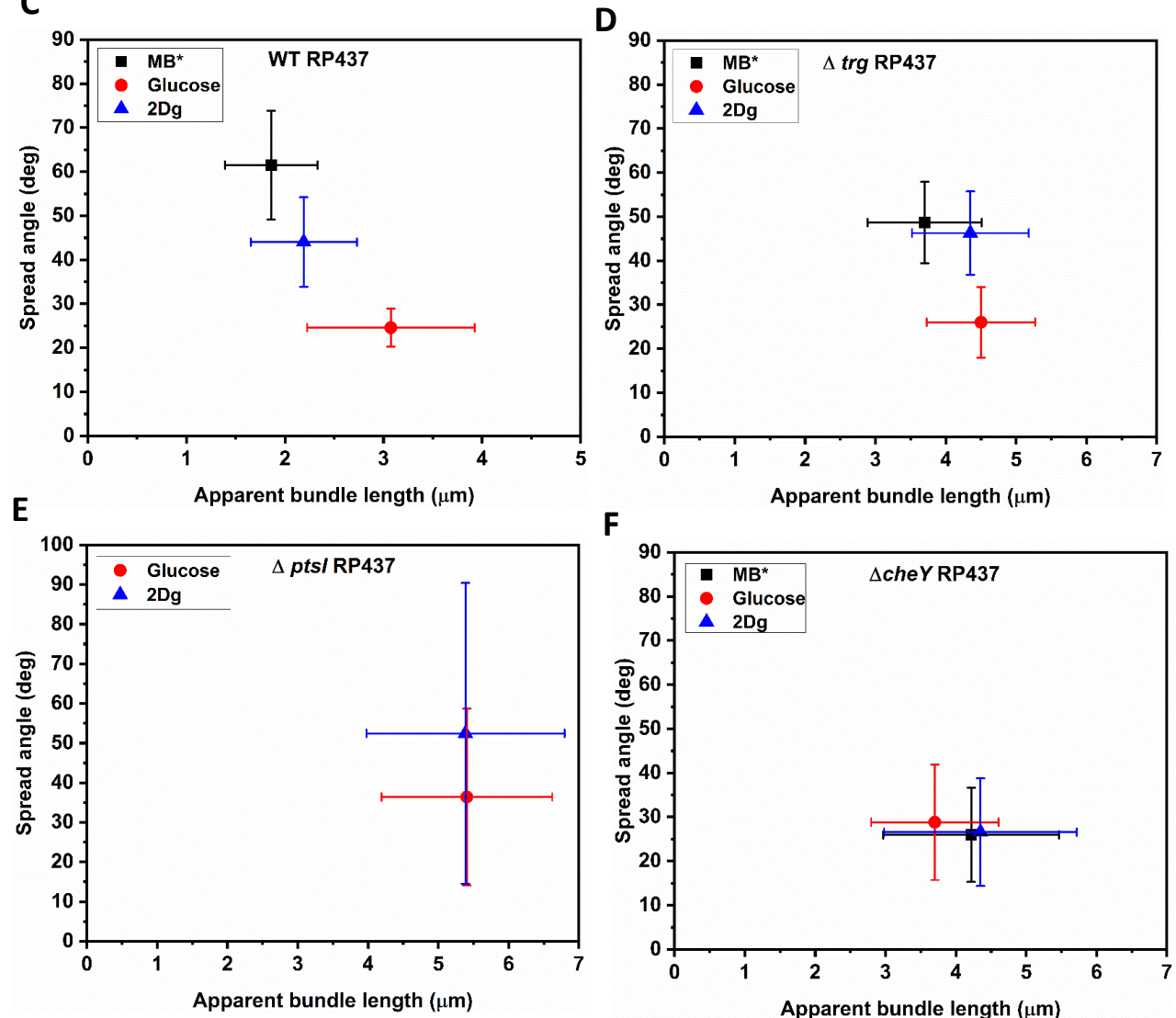

F

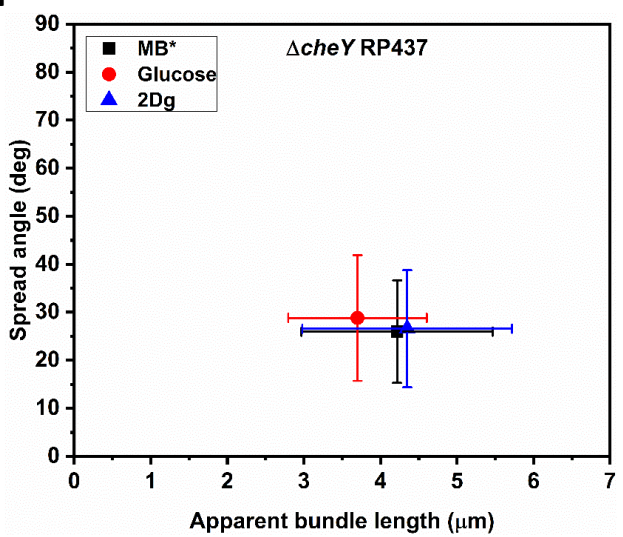

Figure 3: (A) Different configurations of flagellar bundle in WT 1) Stationary cell stuck to the glass showing four flagella. Swimming WT cells in 2) MB* with two flagellar bundles 3) 2Dg shows wider bundle spread at poles 4) Glucose shows tighter bundles at poles. (B) Trajectories of different WT cells in motility buffer shows wiggling while in glucose smooth trajectories were seen. Cells in $2 \mathrm{Dg}$ showed both wiggling as well as smooth trajectories (Scale bar, $2 \mu \mathrm{m}$ ). (C) To characterise bundle geometry, spread angles and length of the flagellar bundle were measured in MB*, $1000 \mu \mathrm{M}$ glucose, and $2 \mathrm{Dg}$ for WT. The spread angles in different ligands were significantly different from $\mathrm{MB}^{*}$ at $p<0.001$ as computed by one-way ANNOVA. (D) In $\Delta \operatorname{trg} \mathrm{RP} 437$, the spread angle values in glucose were significantly different from $\mathrm{MB}^{*}$ at $p<0.001$ as computed by one-way ANNOVA (E) In $\Delta p t s I$ RP437, no data is shown for MB* since cells had no net motion with unbundled flagella. The spread angles in $2 \mathrm{Dg}$ was not significantly different from glucose at $p>0.05$ as computed by one-way ANNOVA (F) $\Delta c h e Y$ RP437. Each data point is an average of 25-40 cells. The data was averaged from three independent cell cultures. 
bioRxiv preprint doi: https://doi.org/10.1101/2021.02.11.430483; this version posted June 11, 2021. The copyright holder for this preprint (which was not certified by peer review) is the author/funder. All rights reserved. No reuse allowed without permission.

the the motility of bacteria [38]. Nevertheless, these factors do not effect the conclusions as we draw all comparisons for glucose and 2Dg with respect to the control buffer subject to identical experimental conditions. Cells in $\mathrm{MB}^{*}$ exhibited mostly irregular bundle formation (including multiple bundles), and thus, the maximum speed was about $9 \mu \mathrm{m} / \mathrm{s}$, which is much lower as compared to glucose and $2 \mathrm{Dg}$. The measured run speed of cells was significantly different in $\mathrm{MB}^{*}$, glucose, and 2Dg with $p<0.01$ as computed by one-way ANNOVA. The apparent bundle length was inversely related to the spread angles (Figure 4B) suggesting that thick bundles are visible more easily.

Swimming speeds were also measured in $\Delta \operatorname{trg}$ RP437 cells and correlated with the spread angle of bundle. There was no difference in run speed and spread angles for cells in either MB* or 2Dg (See supplementary information, S4A). Average run speed in $\mathrm{MB}^{*}$ and $2 \mathrm{Dg}$ was $14.5 \pm 4.5 \mu \mathrm{m} / \mathrm{s}$ (speed \pm standard deviation) whereas in glucose it reached $22.8 \pm 5.6 \mu \mathrm{m} / \mathrm{s}$. This result confirms that sensing via the Trg receptor and metabolism via the PTS uptake pathway, both lead to smaller spread angles. Further, the data presented in Figure 2D and Figure 4A show that the rotational diffusivity of a cell is directly correlated to the bundle spread angle.

\section{Tighter bundles are due to the combined effect of increased motor torque and CCW bias}

$\Delta c h e Y \mathrm{RP} 437$ was studied under ligand conditions similar to that for other strains $(1000 \mu \mathrm{M}$ glucose and $2 \mathrm{Dg}$ ) to probe the effect of increased CCW bias on bundle formation and motility of bacteria. Cells showed low spread angles of $26-29^{\circ} \pm 11^{\circ}$ irrespective of ligand condition. However, run speeds in glucose and 2Dg were significantly different from MB at $p<0.05$ as computed by ANNOVA one-way (Figure 5). These results suggest that an increased motor speed/torque in addition to a constant CCW bias may be responsible for these observations.

We further investigated these observations by determining the motor torque for WT cells, where the cells were tethered on glass slide. We have shown recently that the motor speed increases when the cells sense a ligand and the mechanism is independent of chemotaxis pathway [21]. By measuring the rotational speed of the tethered cell using the same methodology and then calculating the motor torque (see supplementary information for details), we could determine the influence of the ligands on the torque output of individual motors. In WT, the motor torque increased from $380 \mathrm{pN} . \mathrm{nm}$ in MB to 475 pN.nm after $100 \mathrm{~s}$ and 570 pN.nm after 650 seconds of exposure to glucose (Figure $4 \mathrm{C}$ ). Similarly, in response to $2 \mathrm{Dg}$, motor torque increased in single step from about $200 \mathrm{pN} . \mathrm{nm}$ in MB to $300 \mathrm{pN} . n \mathrm{~m}$ at around 300 seconds after exposure to 2Dg (Figure 4D). The increase in torque in response to glucose $(40 \%)$ and $2 \mathrm{Dg}(33 \%)$ was confirmed by averaging over at least 20 cell pairs (Figure 4E-F).

\section{Discussion}

The directional motion of bacteria is dependent on the stability of flagellar bundle which is subjected to intrinsic noise arising from individual flagellar motors. Owing to the nanometer dimension of flagellum and high rotation speed of flagellar bundle $(\approx 100 \mathrm{~Hz})$, it is a challenge to observe the cell body and the geometrical features of the flagellar bundle simultaneously. Hence, much of the previous understanding of the bundling process comes from either simulations or macroscopic scale models $[25,26]$. The bundling has largely been explained by hydrodynamic interactions between flagellum present in a viscous fluid. It is a combination of helix handedness, motor torque and a sense of motor rotation $[25,26,29,40]$. Motor reversals have been attributed to the binding of CheY-P to the motor protein FliM [11] while Berg and others [16,24] have highlighted the morphological transformations of the flagella during bundling and unbundling. However, what has not been investigated is the geometry of flagellar bundle in the presence of ligands, both metabolisable and non-metabolisable, and how these changes influence the swimming trajectory of bacteria. Thus real-time experiments linking changes in bundle geometry due to ligand sensing to the swimming trajectory are largely missing.

To this end, we chose attractants, glucose and its non-metabolisable analogue, 2Dg, which are 
A

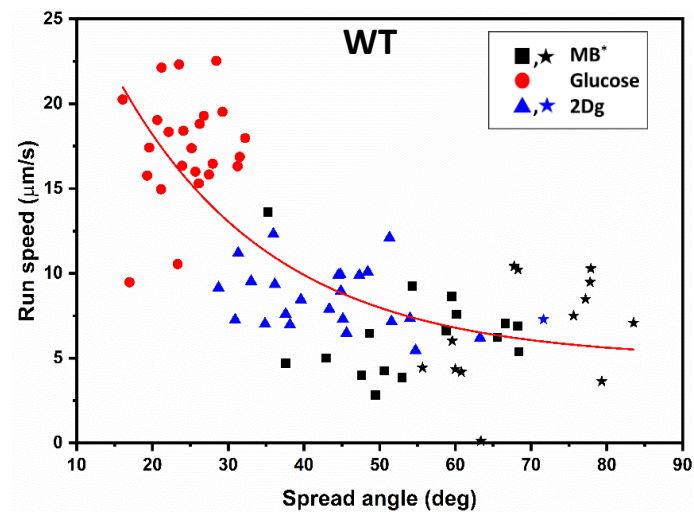

C

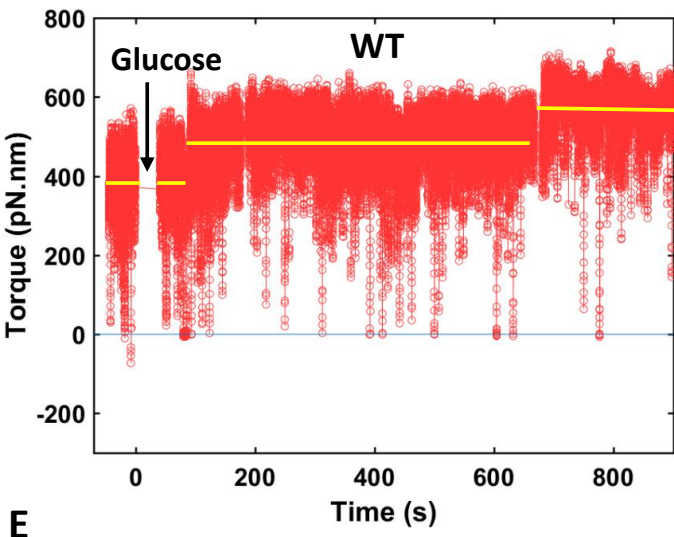

$\mathbf{E}$

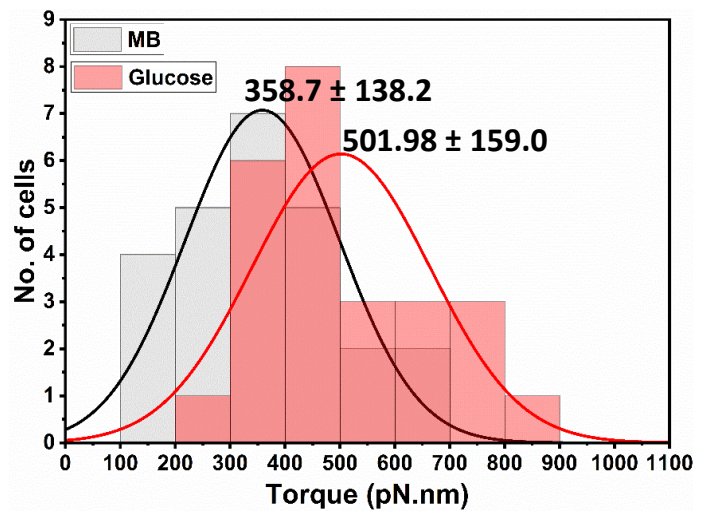

B

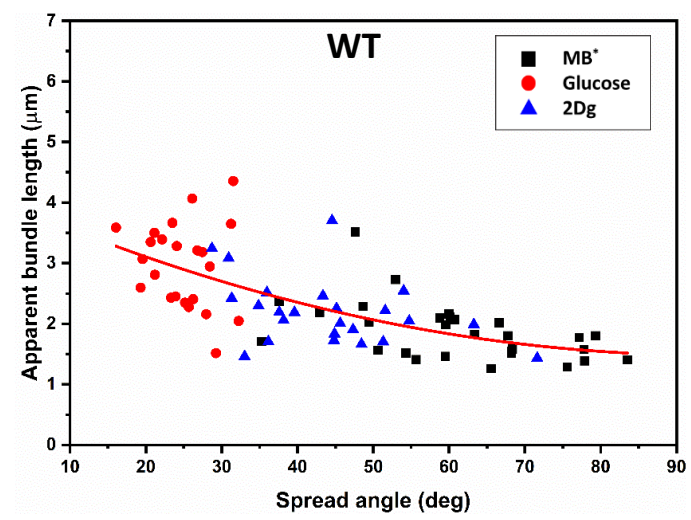

D

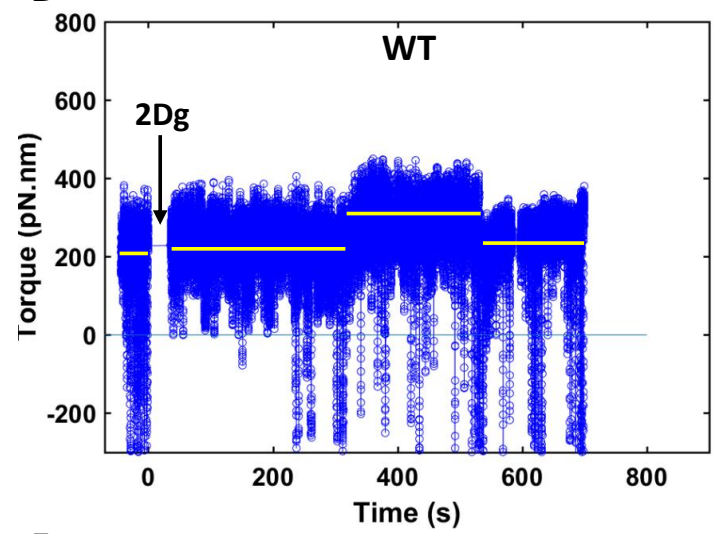

$\mathbf{F}$

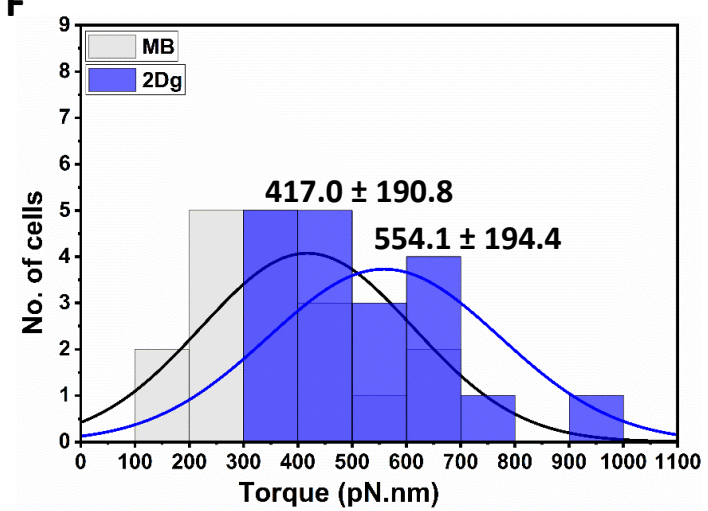

Figure 4: (A) The spread angle attained by WT cell while swimming in $\mathrm{MB}^{*}$, glucose, or 2DG is plotted against its respective run speeds. Cells with higher swimming speeds tend to have the lowest spread angle as evident for glucose, while for $2 \mathrm{Dg}$, values lie in between $\mathrm{MB}^{*}$ and glucose. Speeds in each ligand were significantly different from each other at $p<0.05$ as computed by paired student t-test. Star marked symbol denotes cells having improper bundling, i.e multiple flagellar bundles or unbundled flagellar filaments. (B) Bundle length of each WT cell plotted against its spread angle. Tethered cell experiment with WT cells were performed to determine changes in motor torque initially incubating in $\mathrm{MB}$ and exposed to $1000 \mu \mathrm{M}$ glucose or $1000 \mu \mathrm{M}$ 2Dg. A single motor (WT) showed increase in motor torque when suddenly exposed to (C) $1000 \mu \mathrm{M}$ Glucose (arrows indicate time of introduction). The response was sustained for 900 seconds. (D) $1000 \mu \mathrm{M} 2 \mathrm{Dg}$ but the response was limited to 500 seconds. The torque values depicted are moving average of $0.1 \mathrm{~s}$ (10 frames). Similarly, the torque for more than 20 paired cells that were initially incubating in MB increased when exposed to (E) $1000 \mu \mathrm{M}$ glucose and (F) $1000 \mu \mathrm{M}$ 2Dg. Values for glucose and 2Dg are obtained after $16.5 \mathrm{~min}$ and $6.5 \mathrm{~min}$ of exposure, respectively. The population means and standard deviations are included in the figure. All values are significantly different from MB at $p<0.001$ computed by paired t-test. Data was obtained from four independent experiments. 


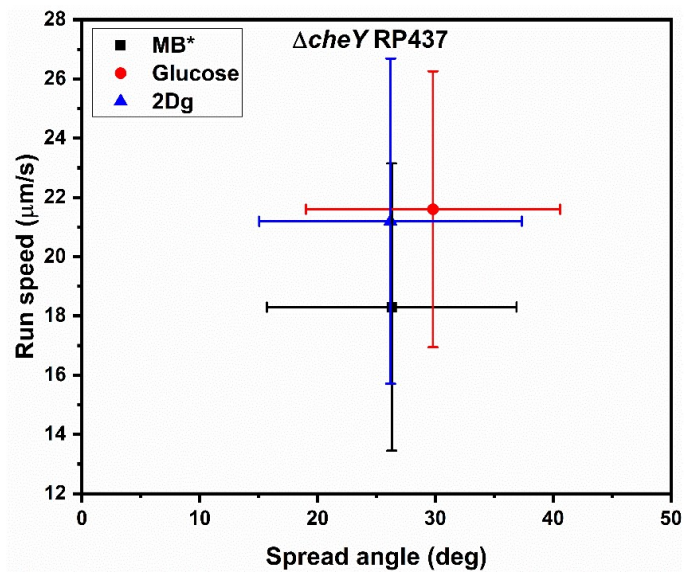

Figure 5: Variation of run speed in response to $1000 \mu \mathrm{M}$ glucose and 2Dg in $\Delta$ cheY RP437 cells. Each data point was an average of 30-35 individual cells. Error bars depict standard deviation. Run speeds in glucose and 2Dg were significantly different from $\mathrm{MB}$ at $p<0.05$ as computed by ANNOVA one-way

both sensed by the Trg receptor. Note that glucose is a preferred carbon source for E. coli and hence is an appropriate ligand to investigate its influence on bundle geometry and the swimming trajectory. We performed a population-level study of WT strain to measure the change in rotational diffusivity in presence of ligands as a function of time. Our experiments with WT strain in glucose showed that the rotational diffusivity $\left(\mathrm{D}_{r}\right)$ reduced with increasing time, an indication that there is reduced wiggle in its swimming trajectory. Even for the non-metabolisable ligand, $\mathrm{D}_{r}$ was decreased by about $35 \%$ (compared to that in MB) for a short time after exposure to the ligand (Figure 2B). The absence of a response to $2 \mathrm{Dg}$ for the $\Delta \operatorname{trg} \mathrm{RP} 437$ strain clearly showed that sensing via receptor influenced the motor motion in WT cells so as to reduce their rotational diffusivity leading to smoother runs. These results were confirmed via control experiments with Trg receptor-deficient strain, where no such change in swimming trajectory was observed upon sensing of 2Dg. However, this was not the case for the $\Delta \operatorname{trg} \mathrm{RP} 437$ strain exposed to glucose. The reduction in rotational diffusivity was similar to that observed in WT, suggesting that the metabolism of glucose via the PTS pathway could also lead to smooth runs (Figure 2B). The inverse relation between $\mathrm{D}_{r}$ and swimming speed was evident from consolidated population data of WT and its mutant strains in different ligands (Figure 2D).

How do cells achieve differential swimming speeds? Does the answer lie in geometrical features of the bundle, which is ultimately responsible for cell propulsion? A flagellum rotates stochastically in either $\mathrm{CW}$ or $\mathrm{CCW}$ direction. The body rotates in opposite direction to balance the torque generated by rotating bundle, therefore interactions between individual flagella becomes important. A stable bundle cannot form if all the flagella change direction continuously which would otherwise lead to jamming. Although it is well known that sensing of ligand increases the CCW bias of flagellar rotation, it is not clear as to how it effects the bundle formation. We performed real-time imaging of $E$. coli WT cells in control motility buffer to visualize the bundle. Swimming cells with loose bundles and in some cases, multiple bundles, were observed. The latter are a common occurrence in multi-flagellated bacteria such as Bacillus subtilis [41] although it has not been reported previously for E.coli.

We quantified the configuration of bundles by measuring two parameters, namely, the spread of filaments around the pole and apparent bundle length. In WT, the majority of cells in MB* had irregular bundles (Figure 3C). Tight bundles (lowest spread angle) were observed for glucose sensing by WT and, trg and che $Y$ mutant strains (Figure 3C-D, F). However, it was not the case for ptsI mutant (Figure 3E) indicating that combined effect of sensing and metabolism results in tight bundles in glucose.

The spread angles for WT in 2Dg were intermediate to those observed in MB* and glucose (Fig- 
bioRxiv preprint doi: https://doi.org/10.1101/2021.02.11.430483; this version posted June 11, 2021. The copyright holder for this preprint (which was not certified by peer review) is the author/funder. All rights reserved. No reuse allowed without permission.

ure 3C). Further, the spread angles matched with those obtained in $\mathrm{MB}^{*}$ for the Trg-receptor deficient strain (Figure 3C). We then asked as to what would happen to the flagellar bundle if all motors rotate exclusively in CCW direction. In this regard, experiments were performed with $\Delta c h e Y$ RP437 [42] and in all three cases $\left(\mathrm{MB}^{*}\right.$, glucose, $2 \mathrm{Dg}$ ), the bundles were tight with low spread angles (Figure $3 \mathrm{~F}$ ). In fact, the spread angle values were similar to those obtained for glucose in WT.

Does tight bundle confer any advantage to a swimming cell? Our study shows that cells respond to attractants by forming tight bundles. Cells with improper bundles (loosely stacked filaments or multiple bundles) result in the slowest run speeds (Figure 4A). Interestingly, when PTS was absent, there was no significant motion in $\mathrm{MB}^{*}$ but cells exhibited directed motion when exposed to 2Dg. This is remarkable because it shows that mere sensing could induce non-motile cells to swim, which goes beyond the current understanding of sensing only influencing the bias of flagellar motor.

A consolidated data of all cells with their spread angles shows an inverse relationship with their corresponding run speeds (see supplementary information, S4B). These results appear contrary to earlier reports $[16,17]$ where it was reported that swimming speeds were not the outcomes of tight or loose bundles [17]. The aforementioned experiments were performed in the presence of glucose [16] and in the presence of methyl cellulose, both of which result in tight bundles and hence it is not possible to obtain a large variability in bundle geometry. While our results clearly show that tight bundles are achieved due to $\mathrm{CCW}$ bias, one of the most important results of the study is that swimming speed can be modulated separately via sensing and metabolism. Experiments with $\Delta$ che $Y$ mutant showed higher swimming speeds in glucose and 2Dg as compared to $\mathrm{MB}^{*}$, even though the motor was rotating continuously in CCW bias (Figure 5).

Similarly, the $\mathrm{D}_{r}$ values for $\Delta$ cheY were reduced in glucose $(57 \%)$ and $2 \mathrm{Dg}(43 \%)$ as compared to $\mathrm{MB}$, confirming that wiggles were further reduced during sensing even though the cells were completely biased to rotate in CCW direction (see supplementary information, S3). Further confirmation of these results was obtained from tethered cell studies with WT which revealed that the motor torques also increased due to sensing (Figure 4C-F). The reported values of torque in $\mathrm{MB}$ for $\mathrm{WT}$ are in agreement with those reported by Darnton et. al [16].

One of the most important observation from this work is that mere sensing of a ligand temporarily increases the motor torque and CCW bias that causes tight flagellar bundles and leads to smooth swimming trajectories with high speeds. This effect was observed even in $\Delta$ che $Y$ mutant strain suggesting that chemotactic pathway is not responsible for the increase in motor speed. Knocking-off the sensor eliminates this effect while the motility of $\Delta p t s I$ mutant cells could be recovered via mere sensing of a ligand. These results clearly indicate the existence of a hitherto unknown signalling pathway that connects the sensor to the motor. In the presence of glucose, where the ligand is both sensed and metabolised, the bundles were the tightest and the highest swimming speeds were achieved. Clearly, E. coli has evolved a complex signalling system that couples to a sophisticated motor and enables the bacteria to respond in varying degrees to changes in its environment.

\section{Materials and Methods}

\section{Bacterial strains and growth condition}

All mutants are derivatives of E. coli RP437 strain as described in Table 1. Mutant strains $\Delta$ trg and $\Delta p t s I$ were developed by following one-step gene inactivation method $[43,44]$ and the details are reported elsewhere [21]. $\Delta c h e Y$ strain was a generous gift from Prof. J. S. Parkinson. Cells were streaked from glycerol stock into tryptone agar plates. A single colony isolate was grown overnight and then sub-cultured in tryptone media $(0.015 \mathrm{~g} / \mathrm{l}$; Sigma) till mid-log phase (OD 600 at $200 \mathrm{rpm}$, $30^{\circ} \mathrm{C}$ ). All experiments were performed at room temperature $23^{\circ} \mathrm{C}$.

\section{Determination of rotational diffusivity and run speeds at the population level}

Bacterial cell culture $(50 \mathrm{ml})$ was centrifuged at $4000 \mathrm{rpm}$ for $10 \mathrm{~min}$ to obtain a pellet. The pellet was washed twice via resuspension in motility buffer (MB). MB is composed of $\mathrm{K}_{2} \mathrm{HPO}_{4}, 11.2 \mathrm{~g}$; $\mathrm{KH}_{2} \mathrm{PO}_{4}, 4.8 \mathrm{~g} ;\left(\mathrm{NH}_{4}\right)_{2} \mathrm{SO}_{4}, 2 \mathrm{~g} ; \mathrm{MgSO}_{4} \cdot \mathrm{H}_{2} \mathrm{O}, 0.25 \mathrm{~g}$; Polyvinylpyrrolidone, $1 \mathrm{~g}$ and EDTA, 0.029 
bioRxiv preprint doi: https://doi.org/10.1101/2021.02.11.430483; this version posted June 11, 2021. The copyright holder for this preprint (which was not certified by peer review) is the author/funder. All rights reserved. No reuse allowed without permission.

Table 1: Bacterial strains used in this study

\begin{tabular}{llll}
\hline Strain & Relevant genotype & Parent strain & Comments, references \\
\hline E. coli RP437 & & & E. coli wild type $[42]$ \\
RP5232 & $\Delta$ cheY & RP437 & {$[42]$} \\
MTKV01 & $\Delta$ trg:: Frt & RP437 & {$[21]$} \\
MTKV04 & $\Delta$ ptsI::Frt & RP437 & {$[21]$} \\
\hline
\end{tabular}

g per liter of distilled water. Cells were introduced in vials containing $\mathrm{MB}, 1000 \mu \mathrm{M}$ glucose, and $1000 \mu \mathrm{M} 2 \mathrm{Dg}$ such that the final bacterial concentration was approximately $10^{6}-10^{7}$ cells $/ \mathrm{mL}$. The cell suspension were introduced into rectangular glass microchannels of dimension, $5 \mathrm{~cm}(\mathrm{~L}) \times 1000$ $\mu \mathrm{m}(\mathrm{W}) \times 100 \mu \mathrm{m}(\mathrm{H})($ VitroCom Inc.) via capillary action. Both the ends of the microchannel were sealed with wax after the introduction of cells. For each sample, a new capillary was used at $0,5,10$, 15 min to measure the change in rotational diffusivity with time. The measurements were done over 3 min.

An inverted microscope (IX71, Olympus ) fitted with Evolution VF cooled Monochrome camera (Media cybernetics, Japan) was used for imaging. Trajectories of swimming bacteria were recorded with 40X (0.75 NA) objective using a dark-field condenser. At each time point, six videos each of about $15 \mathrm{~s}$ duration were recorded over a span of $3 \mathrm{~min}$ at a frame rate of $21 \mathrm{fps}$. Images were taken in the central region of the micro-channel away from the channel walls. The trajectories of the cells were obtained using commercial software, ImageProPlus. The data were analyzed using an in-house code written on MATLAB to obtain the rotational diffusivity from more than 2,500 cells for each condition. We considered cells within $1 \mu \mathrm{m}$ of the focal plane with tracks longer than $0.5 \mathrm{~s}$, which ensured that all out-of-plane motions were ignored by the analysis. A tumble event was identified when the swimming speed of the cell was below half the mean swimming speed, and the change in the turn angle was higher than $4^{\circ}$ between successive frames (at $21 \mathrm{fps)} \mathrm{[45].} \mathrm{The} \mathrm{measured} \mathrm{average} \mathrm{swimming} \mathrm{speed} \mathrm{of}$ $18.2 \pm 7.9 \mu \mathrm{m} / \mathrm{s}$ (average \pm standard deviation) and an average turn angle of $71^{\circ}$ for RP437 cells dispersed uniformly in a micro-channel containing plain motility buffer are close to those observed for the same strain reported earlier, $18.8 \pm 8.2 \mu \mathrm{m} / \mathrm{s}$ and $69^{\circ}$ [39]. The rotational diffusivity is defined as $\mathrm{D}_{r}=\langle\theta\rangle^{2} / 2 t$, where $\theta$ is the angular displacement between two consecutive frames, $\mathrm{t}$ is the time difference between those two frames $(0.047 \mathrm{~s})$ and the brackets represents a grouped average of $\theta$. The details of the analysis have been described in earlier published reports [13,14].

\section{Fluorescent staining of flagella}

Bacterial culture of $\mathrm{OD}_{600} \approx 0.6(10 \mathrm{ml})$ was pelleted by centrifugation $(4000 \mathrm{rpm}, 10 \mathrm{~min})$. Pellet was washed thrice by centrifugation $(2000 \mathrm{rpm}, 10 \mathrm{~min})$ in $\mathrm{pH} 7.0$ Buffer A $\left(0.01 \mathrm{M} \mathrm{KPO}_{4} ; 0.067 \mathrm{M}\right.$ $\mathrm{NaCl} ; 10^{-4} \mathrm{M}$ EDTA; $0.001 \%$ Tween 40 ). After the last wash, cells were resuspended in $250 \mu \mathrm{L}$ Buffer $\mathrm{B}$ (same as Buffer A but adjusted to $\mathrm{pH}$ 7.5) for staining. $20 \mu \mathrm{L}$ of Alexa fluor 488 NHS ester (or succinimidyl ester) (ThermoFisher Scientific, product number-A20000) $(5 \mathrm{mg} / \mathrm{ml})$ was added to cell suspension [34] and the cells were incubated in the dark at $30^{\circ} \mathrm{C}$ for one hour with gentle mixing at $100 \mathrm{rpm}$. Excess dye was removed by washing multiple times in Buffer A (2000 rpm, $10 \mathrm{~min})$. Since maintaining a $\mathrm{pH}$ of 7.0 is critical for stable staining, buffer A was used for dissolving ligands. Hence, for dye experiments $\mathrm{MB}^{*}$ refers to plain buffer A. A dilute suspension of cells was obtained by adding 1 or $2 \mu \mathrm{l}$ of cell pellet in each of $500 \mu \mathrm{l} \mathrm{MB}$, glucose or $2 \mathrm{Dg}$. Cell suspension was then introduced in oxygen permeable device and immediately subjected to imaging. It should be noted that buffer was not exchanged during the experiment and different devices were used for each ligand.

Preparation of slides and image acquisition Rectangular chambers were formed by placing two parallel silicone rubber spacers on glass coverslip. Thin-sheets of PDMS (Polydimethylsiloxane) were placed on top of the spacers. This setting ensures permeability of oxygen to the cells and thus, does not affect the motility of cells due to the oxygen limitation during the course of our experiment. 


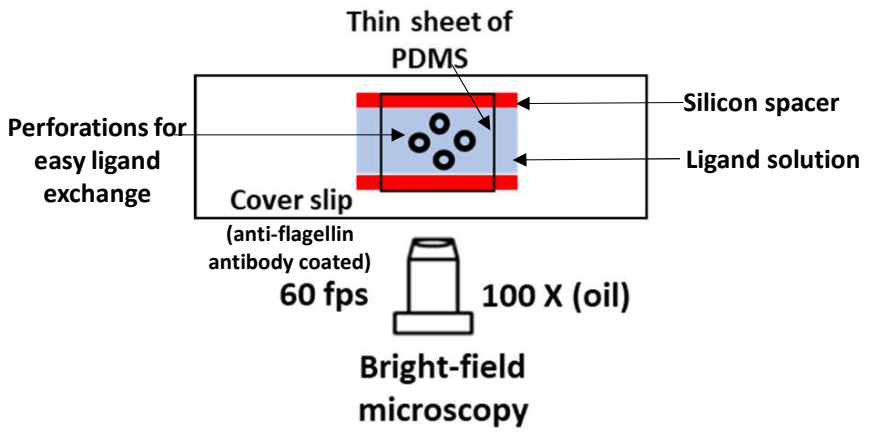

Figure 6: Schematic of setup for tethered cell experiment of E. coli. Cells were first imaged in MB, and then concentrated ligand solution was introduced through holes.

The cell suspension was introduced in these channels. Imaging was done using spinning disc confocal microscopy (Perkin Elmer UltraView system with Olympus IX71) with 100X (1.4 NA) dark phase oil-immersion objective. Setup was excited with $488 \mathrm{~nm}$ wavelength laser and exposed for $46 \mathrm{~ms}$. The system was set at 1-by-1 binning and 40\% laser power. Images were recorded at a speed of $17 \mathrm{fps}$ by an EMCCD camera (Hamamatsu Inc.). Exposure time for each frame was $46 \mathrm{~ms}$. Since average bundle rotation rate is $131 \mathrm{~Hz}$ [16], this means that imaging essentially measured the bundle shape averaged over 5-6 flagellar bundle rotations.

Image Analysis and characterization of flagellar bundles The cell body appeared very bright as compared to flagella. Hence, brightness and contrast were adjusted using ImageJ (NIH) software to visualize flagella distinctly using ImageJ. Individual swimming cells were cropped from the main movie. For each cell, three parameters were measured - spread angle, bundle length, and speed. Spread angle of a bundle at the pole was measured by forming an angle at a fixed distance of $1 \mu \mathrm{m}$ away from it such that the complete bundle is contained within this angle. Bundle length was measured as the distance between the polar end of the cell body and the distal end of the flagellar bundle (see supplementary information, S1A). For each cell, these two parameters were measured in at least three different frames, and an average was computed. The swimming/run speed of cell was measured by determining distance traveled between frames and was calculated using the following equation

$$
\text { Run Speed }=\frac{\sqrt{\left(X_{2}-X_{1}\right)^{2}+\left(Y_{2}-Y_{1}\right)^{2}}}{0.058 \times\left(F_{2}-F_{1}\right)}
$$

where $X_{1}, Y_{1}$ and $X_{2}, Y_{2}$ are coordinates of centroid of cell in frames F1, F2 respectively and 0.058 $\mathrm{s}$ is the time difference between consequent frames. For each strain and ligand condition, 25-40 cells were measured, which is similar to the number of cells used to determine bundle properties in earlier studies [16]. All distances were calibrated by recording images of an objective micrometer.

\section{Determination of motor torque by tethered cell experiment}

Tethered cell experiments were conducted as described in detail previously [21]. Briefly, mid-log phase grown cells were sheared by passing through 21-gauge syringe needle (75 times) and anchored to glass-slide pre-incubated with anti-flagellin antibody (Figure 6). The imaging was done with an inverted microscope (Olympus IX71) fitted with 100X (1.4 NA), oil-immersion objective. Area was scanned for rotating cells and videos were captured at an acquisition rate of $60 \mathrm{fps}$ for 30 to $44 \mathrm{~s}$ using a CMOS camera (Hamamatsu Inc). In order to measure the response of single flagellar motor to ligands, we first measured the response in MB and again after adding glucose/2Dg. Such pair-wise assessment removed any variability arising due to cell size and tethering geometry. The image analysis 
bioRxiv preprint doi: https://doi.org/10.1101/2021.02.11.430483; this version posted June 11, 2021. The copyright holder for this preprint (which was not certified by peer review) is the author/funder. All rights reserved. No reuse allowed without permission.

was done in ImageJ and motor speed calculation were made using in-house MATLAB code described previously [21]. The torque of each rotating cell based on their shape was then calculated as described previously [46] and is detailed in supplementary section.

\section{References}

[1] DePamphilis, M. \& Adler, J. Fine structure and isolation of the hook-basal body complex of flagella from escherichia coli and bacillus subtilis. J Bacteriol 105, 384-395 (1971).

[2] Berg, H. C. The Rotary Motor of Bacterial Flagella. Annu Rev Biochem 72, 19-54 (2003).

[3] Macnab, R. M. \& Ornston, M. K. Normal-to-curly flagellar transitions and their role in bacterial tumbling. stabilization of an alternative quaternary structure by mechanical force. $J$ Mol Biol 112, 1-30 (1977).

[4] Berg, H. C. \& Anderson, R. A. Bacteria swim by rotating their flagellar filaments. Nature 245, 380-382 (1973).

[5] Berg, H. C., Brown, D. A. et al. Chemotaxis in escherichia coli analysed by three-dimensional tracking. Nature 239, 500-504 (1972).

[6] Keller, J. B. \& Rubinow, S. Swimming of flagellated microorganisms. Biophys J 16, 151-170 (1976).

[7] Hyon, Y., Powers, T. R., Stocker, R., Fu, H. C. et al. The wiggling trajectories of bacteria. J Fluid Mech 705, 58-76 (2012).

[8] Thawani, A. \& Tirumkudulu, M. S. Trajectory of a model bacterium. J Fluid Mech 835, 252 (2018).

[9] Blair, D. F. How bacteria sense and swim. Annu Rev Microbiol 49, 489-520 (1995).

[10] Adler, J. Chemoreceptors in bacteria. Science 166, 1588-1597 (1969).

[11] Welch, M., Oosawa, K., Aizawa, S.-l. \& Eisenbach, M. Phosphorylation-dependent binding of a signal molecule to the flagellar switch of bacteria. Proc Natl Acad Sci USA 90, 8787-8791 (1993).

[12] Ahmed, T. \& Stocker, R. Experimental verification of the behavioral foundation of bacterial transport parameters using microfluidics. Biophys J 95, 4481-4493 (2008).

[13] Deepika, D., Karmakar, R., Tirumkudulu, M. S. \& Venkatesh, K. V. Variation in swimming speed of Escherichia coli in response to attractant. Arch Microbiol 197, 211-222 (2014).

[14] Karmakar, R., Naaz, F., Tirumkudulu, M. S. \& Venkatesh, K. V. Escherichia coli modulates its motor speed on sensing an attractant. Arch Microbiol 198, 827-833 (2016).

[15] Uday Bhaskar, R. V., Karmakar, R., Deepika, D., Tirumkudulu, M. S. \& Venkatesh, K. V. Variation of swimming speed enhances the chemotactic migration of Escherichia coli. Syst Synth Biol 9, 85-95 (2015).

[16] Darnton, N. C., Turner, L., Rojevsky, S. \& Berg, H. C. On torque and tumbling in swimming escherichia coli. J Bacteriol 189, 1756-1764 (2007).

[17] Turner, L., Ping, L., Neubauer, M. \& Berg, H. C. Visualizing flagella while tracking bacteria. Biophys J 111, 630-639 (2016).

[18] Leake, M. C. et al. Stoichiometry and turnover in single, functioning membrane protein complexes. Nature 443, 355 (2006). 
bioRxiv preprint doi: https://doi.org/10.1101/2021.02.11.430483; this version posted June 11, 2021. The copyright holder for this preprint (which was not certified by peer review) is the author/funder. All rights reserved. No reuse allowed without permission.

[19] Lele, P. P., Hosu, B. G. \& Berg, H. C. Dynamics of mechanosensing in the bacterial flagellar motor. Proc Natl Acad Sci USA 110, 11839-11844 (2013).

[20] Wadhwa, N., Phillips, R. \& Berg, H. C. Torque-dependent remodeling of the bacterial flagellar motor. Proc Nat Acad Sci USA 116, 11764-11769 (2019).

[21] Naaz, F., Agrawal, M., Chakraborty, S., Tirumkudulu, M. S. \& Venkatesh, K. Ligand sensing enhances bacterial flagellar motor output via stator recruitment. Elife 10, e62848 (2021).

[22] Flores, H., Lobaton, E., Méndez-Diez, S., Tlupova, S. \& Cortez, R. A study of bacterial flagellar bundling. Bull Math Biol 67, 137-168 (2005).

[23] Reichert, M. \& Stark, H. Synchronization of rotating helices by hydrodynamic interactions. Eur Phys J E 17, 493-500 (2005).

[24] Turner, L. et al. Real-Time Imaging of Fluorescent Flagellar Filaments Real-Time Imaging of Fluorescent Flagellar Filaments. J Bacteriol 182, 2793-2801 (2000).

[25] Kim, M., Bird, J. C., Van Parys, A. J., Breuer, K. S. \& Powers, T. R. A macroscopic scale model of bacterial flagellar bundling. Proc Natl Acad Sci USA 100, 15481-15485 (2003).

[26] Macnab, R. M. Bacterial flagella rotating in bundles: a study in helical geometry. Proc Natl Acad Sci USA 74, 221-225 (1977).

[27] Janssen, P. \& Graham, M. Coexistence of tight and loose bundled states in a model of bacterial flagellar dynamics. Phys Rev E 84, 011910 (2011).

[28] Reigh, S. Y., Winkler, R. G. \& Gompper, G. Synchronization and bundling of anchored bacterial flagella. Soft Matter 8, 4363-4372 (2012).

[29] Reigh, S. Y., Winkler, R. G. \& Gompper, G. Synchronization, slippage, and unbundling of driven helical flagella. PloS one 8, e70868 (2013).

[30] Lee, W., Kim, Y., Griffith, B. E. \& Lim, S. Bacterial flagellar bundling and unbundling via polymorphic transformations. Phys Rev E 98, 052405 (2018).

[31] Lim, S. \& Peskin, C. S. Fluid-mechanical interaction of flexible bacterial flagella by the immersed boundary method. Phys Rev E 85, 036307 (2012).

[32] Mears, P. J., Koirala, S., Rao, C. V., Golding, I. \& Chemla, Y. R. Escherichia coli swimming is robust against variations in flagellar number. Elife 3, e01916 (2014).

[33] Stocker, R. Reverse and flick: Hybrid locomotion in bacteria. Proc Natl Acad Sci USA 108, 2635-2636 (2011).

[34] Turner, L., Zhang, R., Darnton, N. C. \& Berg, H. C. Visualization of flagella during bacterial swarming. J Bacteriol 192, 3259-3267 (2010).

[35] Adler, J., Hazelbauer, G. L. \& Dahl, M. M. Chemotaxis toward sugars in Escherichia coli. J Bacteriol 115, 824-847 (1973).

[36] Neumann, S., Grosse, K. \& Sourjik, V. Chemotactic signaling via carbohydrate phosphotransferase systems in Escherichia coli. Proc Natl Acad Sci 109, 12159-12164 (2012).

[37] Sourjik, V. \& Wingreen, N. S. Responding to chemical gradients: bacterial chemotaxis. Curr Opin Cell Biol 24, 262-268 (2012).

[38] Macnab, R. \& Koshland Jr, D. Bacterial motility and chemotaxis: light-induced tumbling response and visualization of individual flagella. J Mol Biol 84, 399-406 (1974). 
bioRxiv preprint doi: https://doi.org/10.1101/2021.02.11.430483; this version posted June 11, 2021. The copyright holder for this preprint (which was not certified by peer review) is the author/funder. All rights reserved. No reuse allowed without permission.

[39] Saragosti, J. et al. Directional persistence of chemotactic bacteria in a traveling concentration wave. Proc Natl Acad Sci USA 108, 16235-16240 (2001).

[40] Qu, Z., Temel, F. Z., Henderikx, R. \& Breuer, K. S. Changes in the flagellar bundling time account for variations in swimming behavior of flagellated bacteria in viscous media. Proc Natl Acad Sci USA 115, 1707-1712 (2018).

[41] Najafi, J., Altegoer, F., Bange, G. \& Wagner, C. Swimming of bacterium bacillus subtilis with multiple bundles of flagella. Soft matter 15, 10029-10034 (2019).

[42] Parkinson, J. S. Complementation analysis and deletion mapping of escherichia coli mutants defective in chemotaxis. J Bacteriol 135, 45-53 (1978).

[43] Baba, T. et al. Construction of Escherichia coli K-12 in-frame, single-gene knockout mutants : the Keio collection. Mol Syst Biol 4474, 1-11 (2006).

[44] Datsenko, K. A. \& Wanner, B. L. One-step inactivation of chromosomal genes in Escherichia coli K-12 using PCR products. Proc Natl Acad Sci USA 97, 6640-6645 (2000).

[45] Alon, U. et al. Response regulator output in bacterial chemotaxis. EMBO J 17, $4238-4248$ (1998).

[46] Che, Y.-S. et al. Suppressor analysis of the motb (d33e) mutation to probe bacterial flagellar motor dynamics coupled with proton translocation. J Bacteriol 190, 6660-6667 (2008).

\section{Acknowledgments}

We thank Prof. John S. Parkinson for providing us with E. coli RP437 wild-type and its cheY deletion mutant strains. Financial support from the Department of Science and Technology, India (SB/S3/CE/089/2013) and Department of Biotechnology, India

(BT/PR7712/BRB/10/1229/2013) is acknowledged.

\section{Author contribution}

M.A., S.C., M.S.T. and K.V.V. designed research; M.A. and S.C. performed research; M.A., M.S.T. and K.V.V analyzed data; and M.A., M.S.T. and K.V.V. wrote the paper.

\section{Additional information}

Supplementary information accompanies this paper.

Competing interests: The authors declare no conflict of interest. 